\title{
FORMAÇ̃̃O CONTINUADA DE PROFESSORES EM CENÁRIOS BRASILEIRO E PORTUGUÊS: PROCEDÊNCIAS E QUALIFICADORES DA ATIVIDADE EXPERIMENTAL PROBLEMATIZADA (AEP)
}

\author{
CONTINUING EDUCATION FOR TEACHERS IN BRAZILIAN AND PORTUGUESE SCENARIOS: \\ PROCEDURES AND QUALIFIERS OF PROBLEMATIZED EXPERIMENTAL ACTIVITY (PEA)
}

\author{
ANDRÉ LUÍS SILVA DA SILVA ${ }^{1}$ \\ PAULO ROGERIO GARCEZ DE MOURA ${ }^{2}$ \\ JOSÉ CLÁUDIO DEL PINO ${ }^{3}$
}

\section{RESUMO}

Neste artigo, a Atividade Experimental Problematizada (AEP) é retomada como constituindo-se de uma estratégia voltada ao ensino experimental das Ciências, sob as bases teóricas da Teoria da Aprendizagem Significativa e Epistemologia de Thomas Kuhn, e protocolo de sistematização próprios, os quais a caracterizam e a definem. Em um contexto de formação continuada de professores, brasileiros e portugueses, tratou-se dos fundamentos da AEP, de modos dialogado e discursivo. Utilizando-se do software Mentimenter e da técnica Análise Textual Discursiva, foram recuperados da fala dos envolvidos determinados argumentos que reforçam a experimentação, de um modo amplo, como uma estratagema didática amplamente favorável ao Ensino de Ciências potencialmente gerador de aprendizagens cognitivas. Nas especificidades da AEP, identificaram-se elementos capazes de favorecer tal propósito, ao caracterizar a Ciência como um empreendimento humano e socialmente constituído.

Palavras-chave: Experimentação. Ensino de Ciências. Metodologia de Ensino.

\section{ABSTRACT}

In this article, the Problematic Experimental Activity (PEA) is resumed as constituting a strategy aimed at the experimental teaching of Sciences, under theoretical bases of the Meaningful Learning Theory and Thomas Kuhn's Epistemology, and their own systematization protocol, which characterize and define it. In a context of continuing education for teachers, Brazilians and Portuguese, the fundamentals of PEA were dealt with in a dialogical and discursive way. Using the Mentimenter software and the Discursive Textual Analysis technique, certain arguments that reinforce experimentation were broadly recovered from the speech of those involved, in a broad way, as a didactic stratagem broadly favorable to Science Teaching, potentially generating cognitive learning. In the specificities of the PEA, elements capable of favoring this purpose were identified, by characterizing Science as a human and socially constituted enterprise.

Keywords: Experimentation. Science teaching. Teaching Methodology.

\section{RESUMEN}

En este artículo se retoma la Actividad Experimental Problemática (AEP) como una estrategia orientada a la enseñanza experimental de las Ciencias, bajo bases teóricas de la Teoría del Aprendizaje Significativo y Epistemología de Thomas Kuhn, y su propio protocolo de sistematización, que caracteriza y definirlo. En un contexto de formación continua

\footnotetext{
1 Doutor em Educação em Ciências pela Universidade Federal do Rio Grande do Sul (UFRGS). Professor Adjunto da Universidade Federal do Pampa (Unipampa), Caçapava do Sul, Rio Grande do Sul. Email: andresilva@unipampa.edu.br. ORCID: https://orcid.org/0000-0002-8245-9389.

2 Doutor em Educação em Ciências pela Universidade Federal do Rio Grande do Sul (UFRGS). Professor Adjunto da Universidade Federal do Espírito Santo (UFES), Vila Velha, Espírito Santo. Email: paulomoura.ufes@gmail.com. ORCID: https://orcid.org/0000-0003-2659-5383.

3 Doutor em Engenharia de Biomassa pela Universidade Federal do Rio Grande do Sul (UFRGS). Professor Associado da Universidade Federal do Rio Grande do Sul (UFRGS), Porto Alegre, Rio Grande do Sul. Email: delpinojc@yahoo.com.br. ORCID: https://orcid.org/0000-0002-8321-9774.
} 
para docentes, brasileños y portugueses, se abordaron los fundamentos de la AEP, de forma dialógica y discursiva. Utilizando el software Mentimenter y la técnica de Análisis Textual Discursivo, se reforzaron ciertos argumentos en el discurso de los involucrados que refuerzan la experimentación, de manera amplia, como una estratagema didáctica ampliamente favorable a la Enseñanza de las Ciencias, potencialmente generadora de aprendizajes cognitivos. En las especificidades de la AEP se identificaron elementos capaces de favorecer tal propósito, al caracterizar a la Ciencia como una empresa humana y socialmente constituida.

Palabras-clave: Experimentación. Enseñanza de las ciencias. Metodología de enseñanza.

\section{INTRODUÇÃO}

A Atividade Experimental Problematizada (AEP) configura-se como uma proposta de sistematização teórico-metodológica voltada ao ensino experimental das Ciências. Está materializada originalmente pela publicação de duas obras bibliográficas, sendo que, na primeira, Silva e Nogara (2018) apresentam exemplificações de AEPs no contexto do ensino da Química e, na segunda, Silva e Moura (2018) a estendem às demais Ciências Naturais, fundamentando-a pedagógica e epistemologicamente. Outrossim, desde 2015 artigos versam sobre a temática em âmbitos de ensino e de aprendizagem das Ciências, em diferentes contextos e públicos-alvo (SILVA, MOURA; DEL PINO, 2015; 2017; 2018; SILVA et al., 2019; MOREIRA; SILVA, MOURA; DEL PINO, 2019).

A AEP é apresentada neste artigo como uma proposta de ensino-aprendizagem, nas particularidades das Ciências experimentais, que se desenvolve a partir da demarcação de um problema de natureza teórica, isto é, como uma atividade prática que objetiva a busca por uma solução justificável a dada situação-problema. Sendo assim, pode-se inferir a precedência de experimentar um problema a problematizar um experimento.

Na conjuntura didático-pedagógica de uma AEP, o próprio problema exposto ao aluno pode despertar nele sua motivação, interesse, desafio intelectual e capacidade de articulação de ideias e de discussão, promovendo a autoconfiança necessária para que busque apresentar explicações idiossincráticas aos fenômenos/situações observados. Todavia, para que essa metodologia de ação possa lograr êxito, o professor não deve fornecer (e tampouco esperar por) respostas peremptórias, mas processualmente novos questionamentos e desafios, no intuito de levar o aluno a paulatinamente qualificar seu próprio entendimento. Nessa dinâmica, o professor assume a função de questionador, conduzindo perguntas e propondo novos problemas aos seus alunos, auxiliando-os na exploração, desenvolvimento e adequação constante de suas próprias concepções, para que eles venham a sugerir hipóteses e justificativas às aparentes inconsistências com as quais se deparam (GALIAZZI e GONÇALVES, 1994; HODSON, 1994).

A partir dessa concepção, uma AEP visa propiciar aos alunos sua capacidade de autonomia, ao realizarem registros, discutirem resultados, levantarem hipóteses, avaliarem possíveis explicações e discutirem, dentre seus pares e com o professor, métodos, justificativas e abrangências circunscritas ao experimento que desenvolvem. Essa atividade, contudo, deve ser metodizada, visando a promoção de uma análise reflexiva desde sua origem. Sob essa ótica, a função do professor não mais se configura como centralizador e fornecedor das respostas e das certezas; antes, deve problematizar com seus alunos suas concepções e observações, as amplas leituras do experimento, auxiliando-os a reconhecer a necessidade premente de outros saberes/fazeres e, por conseguinte, a importância do diálogo reflexivo e da pesquisa orientada na busca por uma coerente interpretação das observações empíricas. Nos termos de Zucco (2007, p. 77), 
A interpretação de cada experiência é tentada pelos alunos e pelo professor, à medida que a própria curiosidade do aluno leve este a chamar o professor e perguntar-lhe o que está ocorrendo. É claro que muitas vezes ocorre ao professor não conseguir interpretar de imediato o que se passa, mas é justamente aí que a aula fica mais rica. É nesse momento, em que aluno e professor põem as suas cabeças a trabalhar em conjunto, que 0 aprendizado se dá com maior intensidade. É nesse momento que 0 aluno participa intensamente da aula e aprende.

0 aporte teórico da AEP caracteriza os alunos como sujeitos que desenvolvem conhecimentos em um processo no qual o professor assume e desempenha o papel de orientador, cuja genuinidade é específica, mas abrangente. Cabe assim a constante supervalorização das perguntas em relação às suas possíveis respostas, em um movimento pedagógico dinâmico. Em conformidade ao que destaca Santos (2008, p. 126), "[...] o papel do professor não está em revelar a realidade aos educandos, mas em ajudá-los a desvendar a realidade por si só". Sob esse enfoque, torna-se oportuna a compreensão de que o objetivo da experimentação não deve aproximar-se de padronizações, mas despertar no aluno uma concepção crítica e reflexiva da realidade, bem como sua capacidade de tomada de decisões, que o auxilie, tanto cognitivamente na compreensão do fenômeno em si quanto socialmente, na transposição que poderá fazer dos saberes tratados. Com isso, métodos, resultados e conclusões heterogêneos devem ser aceitos e incentivados, sendo que, de acordo com Latour e Woolgar (1997, p. 61), "[...] na verdade, os fenômenos dependem do material, eles são totalmente constituídos pelos elementos utilizados no laboratório".

\section{Estrutura teórico-metodológica organizadora da AEP4}

Ao se compreender a imprescindibilidade de uma fundamentação teórico-metodológica a toda intervenção de ensino com fins de aprendizagem, propõe-se como e denomina-se de Atividade Experimental Problematizada (AEP) uma estratégia didático-pedagógica ao ensino experimental das Ciências, configurada em dois principais eixos, um de natureza teórica e outro metodológica, associativos e potencialmente indissociáveis. Mostra-se no Quadro 1, em síntese, seus fundamentos denotativos, tratados como eixos teórico (e seus Articuladores) e metodológico (e seus Momentos).

Quadro 1 - Elementos denotativos da AEP, teóricos e metodológicos.

\begin{tabular}{|c|c|c|c|}
\hline \multicolumn{4}{|c|}{ Eixos } \\
\hline & TEÓRICO & & METODOLÓGICO \\
\hline $\begin{array}{l}\text { yे } \\
\frac{0}{0} \\
\frac{0}{0} \\
\frac{0}{3} \\
\frac{0}{4}\end{array}$ & $\begin{array}{l}\text { a. Proposição de problema } \\
\text { b. Objetivo experimental } \\
\text { c. Diretrizes metodológicas }\end{array}$ & ๕ั & $\begin{array}{l}\text { i. Discussão prévia } \\
\text { ii. Organização/desenvolvimento } \\
\text { iii. Retorno ao grupo de trabalho } \\
\text { iv. Socialização } \\
\text { v. Sistematização }\end{array}$ \\
\hline
\end{tabular}

Fonte: adaptado de Silva e Moura (2018, p. 103).

4 Para um maior detalhamento dos elementos caracterizadores dos eixos teórico e metodológico da AEP, ver Silva, A. L. S.; Moura, P. R. G. e Nogara, P. A. Um modelo de sistematização à experimentação no Ensino de Ciências: Atividade Experimental Problematizada (AEP). Revista Research, Society and Development. V. 9, № 7. 2020, disponível em https://rsd.unifei.edu.br/index.php/rsd/article/view/4012. 
Considera-se como eixo teórico da AEP, em seus elementos articuladores, uma configuração que se estrutura a partir da demarcação, elucidação e proposição de um problema de natureza teórica, isto é, uma AEP conforma-se teoricamente como uma estratégia de busca por solução a dada situação-problema. A partir de então, são elaborados um objetivo experimental, tratando-se, sob uma perspectiva abrangente, do que se espera desenvolver empiricamente em termos de produto/ ação experimental, e diretrizes metodológicas, orientações às ações que potencialmente resultarão no referido produto/ação experimental de interesse. Em síntese, a proposta de ensino experimental cunhada como AEP propõe uma articulação entre objetivo experimental e diretrizes metodológicas, a partir da proposição e da análise crítica de um problema, para o qual se buscará a possibilidade de solução, nesse caso particular, pelo emprego metodológico da experimentação.

Essa tessitura, representada na Figura 1, consubstancia-se na Epistemologia de Thomas Kuhn (ETK), tendo em vista seus aspectos teóricos que demarcam o conhecimento científico como não determinista, construído socialmente e favorecido por uma adaptação teoria-experimento e por um protocolo empírico (KUHN, 1998; 2000).

Figura 1 - Articuladores teóricos em seus subsídios epistemológicos.

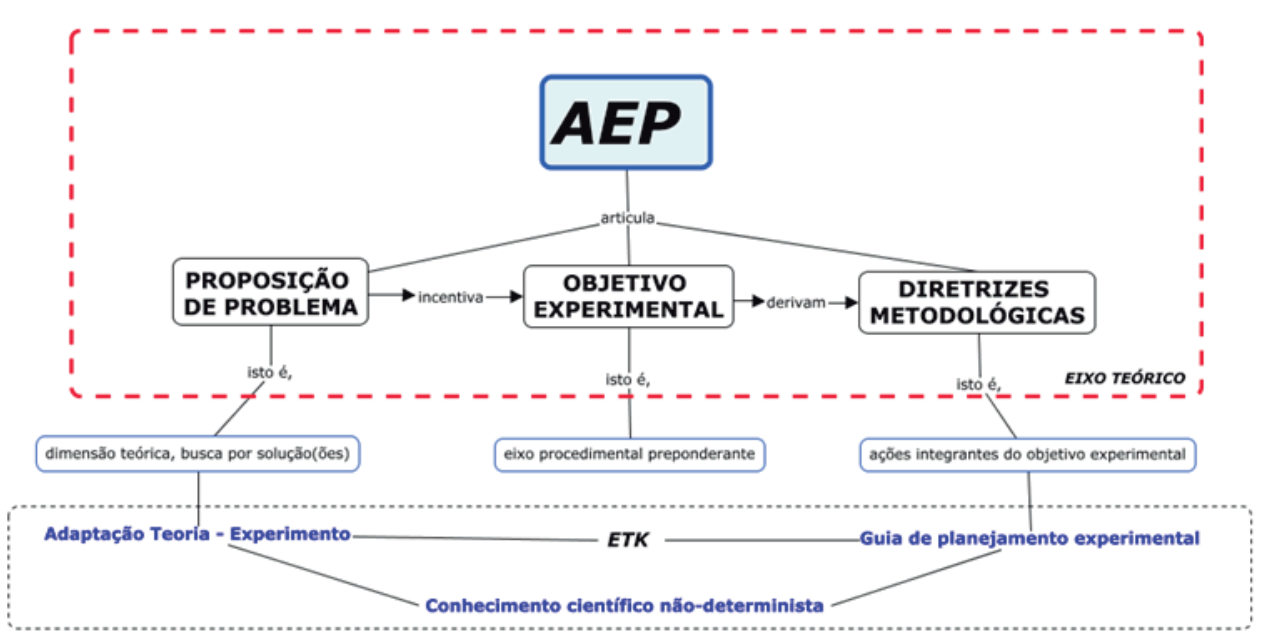

Fonte: adaptado de Silva e Moura (2018, p. 104).

Amparando-se pelos subsídios epistemológicos subjacentes à AEP, tem-se na ETK aportes teóricos que defendem a experimentação como uma atividade capaz de favorecer uma compreensão da Ciência epistemologicamente contemporânea, isto é, capazes de apresentá-la como socialmente construída e aberta a concepções distintas, substanciadas por fatores objetivos e subjetivos adjacentes às atividades desenvolvidas. Contudo, verifica-se que o conhecimento científico ainda é, hodiernamente, disseminado e percebido como determinista (CHALMERS, 1999). No entanto,

[...] as escolhas, as possibilidades, a incerteza, são ao mesmo tempo propriedades do universo e (também) são próprias da existência humana. Elas abrem novas perspectivas para a ciência e uma nova racionalidade, aonde a verdade científica não mais é sinônimo de certo, ou determinado, e aonde o incerto e o indeterminado não estão baseados na ignorância, no desconhecimento. [...] A marca do nosso tempo 
é uma ciência em que o ser e a estabilidade deram passagem para a evolução e a mudança (PRIGOGINE, 2002, p. 21).

Sendo assim, concepções epistemológicas capazes de romper com uma tradição de Ciência empirista-indutivista são imprescindíveis a uma orientação pedagógica capaz de subsidiar seus processos de ensino-aprendizagem. Ao se considerar que as concepções de Ciências que os professores dispõem implicam, explicita ou implicitamente, no modo como planejam e ensinam, em relação às atividades práticas-laboratoriais, em não raras vezes, se verifica que

[...] os estudantes executam tarefas sem saber para onde caminham e que respostas hão de dar e a quê. Parece - e parece-lhes - que os conhecimentos surgem claros, óbvios e não precisam ser interrogados e têm uma resposta que surge natural. Essa é a pior maneira de usar um bom instrumento de aprendizagem (PRAIA; CACHAPUZ; GIL-PÉREZ, 2002, p. 130-131).

Em contrapartida, a concepção de uma Ciência permissiva a compreensões psicológicas (próprias, idiossincráticas) favorece uma pedagogia capaz de aproximar tais fundamentos de seus aprendizes, e articular teoria e prática. Sendo assim, a AEP, tendo em vista esse paradigma, propõe um planejamento teórico à experimentação, bem como a elaboração de uma sistemática prática para dada situação-problema.

Atendendo ao eixo metodológico da AEP, são demarcadas cinco etapas, caracterizadas como momentos: discussão prévia, organização/desenvolvimento da atividade experimental, retorno ao grupo de trabalho, socialização e sistematização, presumidos como imprescindíveis a uma atividade de ensino que ofereça subsídios metodológicos aos aspectos teóricos da AEP. Outras ações, entretanto, de natureza complementar ou ampliativa, poderão ser incorporadas, tomando-se como pressuposto suas contribuições à inteligibilidade no que se refere aos objetos/objetivos de conhecimento/ aprendizagem e adequação sistêmica do método à práxis do professor, potencialidade cognitiva dos alunos e a outros fatores imensuráveis e/ou subjetivos.

Este protocolo metodológico, representado na Figura 2, articula-se à Teoria da Aprendizagem Significativa (TAS), atentando para determinados conceitos/princípios dela originários, tais como existência de três imperativos a uma aprendizagem caracterizada como significativa (estrutura cognitiva específica, material potencialmente significativo e pré-disposição em aprender) e modos distintos germinadores de aprendizagens: por descoberta e por recepção (AUSUBEL, 2003).

Tensionando os subsídios pedagógicos subjacentes à AEP, tem-se na TAS os fundamentos teórico-metodológicos capazes de caracterizá-la como uma estratégia de ensino com foco na aprendizagem, nas particularidades da experimentação das Ciências. Em seu núcleo central, a teoria atrela a aprendizagem a três condições, concomitantes e indissociáveis: (i) estrutura cognitiva específica, (ii) material potencialmente significativo e (iii) pré-disposição do sujeito em aprender. Em (i), sugere-se que 0 aprendiz poderá aprender de modo significativo ao relacionar novas informações com seu conhecimento prévio, isto é, ao possuir e/ou desenvolver subsunçores, elementos cognitivos capazes de oferecer significados psicológico e idiossincrático àquilo que the é apresentado. Vincula-se à (ii) uma abordagem conteudinal sob fundamentos lógico e coerente, isto é, às estratégias didáticas utilizadas pelo professor em sua práxis docente. Com relação à (iii), impõe-se à aprendizagem significativa uma disposição/mobilização própria do sujeito em aprender, a qual pode ser favorecida pelos 
méritos das condições anteriores, mas não garantida (AUSUBEL, 2003; AUSUBEL; NOVAK; HANESIAN, 1980; MOREIRA, 1983; 2006).

Figura 2 - Momentos metodológicos em seus subsídios pedagógicos.

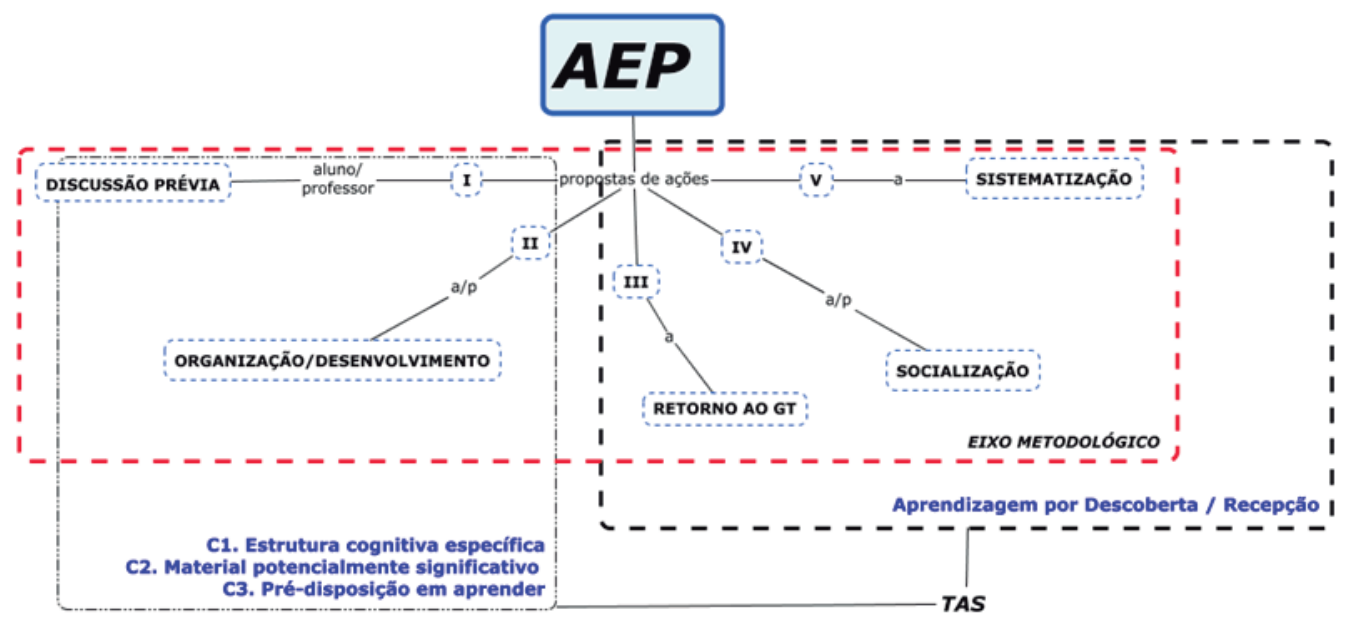

Fonte: Adaptado de Silva e Moura (2018, p. 108).

A TAS ainda aponta para possibilidades de aprendizagens significativas por descoberta e por recepção. Na primeira, objetos de aprendizagens não são apresentados aos sujeitos em seu formato final, definitivo, mas são desvendados em caracterizações e propriedades a partir das relações que por/entre eles são estabelecidas. Em uma aprendizagem do segundo tipo, por sua vez, objetos de conhecimento, conteúdos curriculares em Ciências, por exemplo, são apresentados aos potenciais aprendizes em seu formato concludente, cabendo a eles a proposição de significados psicológicos próprios, mesmo que emergentes de uma única e conhecida caracterização. Nenhum tipo prevalece em mérito, contudo, o segundo é mais corriqueiro em sala de aula e nos laboratórios técnicos ou didáticos (MOREIRA, 2006).

Por fim, considera-se a AEP como uma estratégia capaz de encerrar as três condições supracitadas à aprendizagem com status de desenvolvimento de significados, destacando-se as temáticas científicas, em dados momentos por descoberta, em outros por recepção. Essa apreciação é fundamentada pelos resultados desse artigo, obtidos a partir dos métodos dos quais se passará a tratar.

\section{DIRETRIZES METODOLÓGICAS}

Este artigo apresenta resultados emergentes de uma pesquisa do tipo intervenção pedagógica, nos pressupostos de Damiani et al. (2013), em três contextos/públicos-alvo distintos: (i) discentes - professores da Educação Básica - do Mestrado Profissional em Ensino de Ciências, campus Bagé- Caçapava do Sul-Dom Pedrito, desenvolvido pela Universidade Federal do Pampa (Unipampa), (ii) professores da Educação Básica do Estado do Rio Grande do Sul em Programa de Formação Continuada na modalidade da extensão universitária da Unipampa e (iii) professores-orientadores vinculados à Universidade portuguesa do Minho (UMinho), das áreas de Ciências e Meio Ambiente. Para efeitos de inteligibilidade, respectivamente, se utilizará das codificações PMP (professores, mestrado, 
profissional), PFC (professores, formação, continuada) e PUP (professores, universidade, Portugal) ao se referir aos sujeitos cujo realidade foi pesquisada/alterada. No contexto (i) a atividade foi desenvolvida no âmbito da componente curricular obrigatória de Seminários Especiais I do referido Programa de Pós-Graduação, no primeiro semestre de 2020, no ambiente virtual da plataforma GoogleMeet, onde participaram em torno de 10 docentes. Em (ii) foi proposto um minicurso para aproximadamente 20 docentes, realizado no primeiro semestre de 2020, igualmente desenvolvido no ambiente virtual da plataforma GoogleMeet. Em relação à (iii), desenvolveram-se conferências, em formato dialogado, no segundo semestre de 2020, utilizando-se da plataforma Zoom, junto a um grupo de 14 docentes portugueses. Nos três contextos, propôs-se uma discussão dialogada referente aos aspectos estruturadores da AEP, em seus subsídios pedagógicos, epistemológicos, estrutura teórica (planejamento da AEP) e metodológica (mediação da AEP), com duração aproximada de 4 horas cada.

Seguiu-se pela aplicação de um questionário virtual, cujo instrumento de produção de dados utilizado foi o software Mentimenter (disponível, na "versão do professor", em https://www.mentimeter.com/s/ 7fa63a8388ccb6070c7b83b4948c900f/d29afee6bb3 e na "versão do aluno" em www.menti.com). Por meio deste recurso é possível, de modo síncrono, sistematizar e socializar com o grupo de trabalho pesquisado suas respostas geradas a cada questionamento, tornando-as parâmetro para recuperação de discussões ou instauração de novas, bem como avaliação de ideias emergentes.

0 questionamento/proposição argumentativa foi tratado(a) em cada contexto de aplicação: Você considera a experimentação uma metodologia de ensino que favorece aprendizagens em Ciências? Caso sim, justifique seu posicionamento. Obteve-se sentenças abreviadas como respostas, as quais foram sistematizadas em um único quadro-frame para discussão.

Como instrumento de análise de dados, se fez uso da técnica da Análise Textual Discursiva (ATD), nos pressupostos de Moraes e Galiazzi (2006), por meio da qual é possível identificar unidades de correspondência e, a partir delas, elencar categorias apropriadas para análise, discursivas nos parâmetros pretendidos, em conformidade aos interesses de pesquisa. 0 método da ATD é composto pelas etapas da Desconstrução e Unitarização, Categorização e Metatexto. A primeira delas, Desconstrução e Unitarização, consiste de leituras atentas, aprofundadas e pormenorizadas dos textos, denominados pelos autores de corpus da pesquisa, com foco na busca por percepções de relações de coerência, seguidas pelas suas fragmentações em unidades de significados. Sendo assim, os textos devem ser "[...] recortados, pulverizados, desconstruídos, sempre a partir das capacidades interpretativas do pesquisador" (MORAES; GALIAZZI, 2006, p. 132). Na segunda etapa da ATD, a Categorização, busca-se construir relações entre conceitos, tendo em vista associações explícitas e/ou implícitas existentes - ou notadas - nos textos. "A categorização é um processo de comparação constante entre as unidades definidas no processo inicial da análise, levando a agrupamentos de elementos semelhantes" (MORAES e GALIAZZI, 2006, p. 197). Tais categorias de análise podem ser do tipo a priori, quando definidas previamente, ou emergentes, quando identificadas ao desenrolar da análise, esta descaracterizada de intenções de pesquisa explícitas. Por fim, os Metatextos, terceira, e etapa conclusiva da ATD, segundo Moraes (2003, p. 202), "[...] são constituídos de descrição e interpretação, representando o conjunto de um modo de compreensão e teorização dos fenômenos investigados", compondo-se de elementos genuínos do objeto de análise, de fundamentações teóricas de suporte e das percepções próprias do pesquisador.

Para sistematização dos dados e maior inteligibilidade de sua análise, os três contextos de intervenção foram combinados em torno do questionamento empregado, tendo este sido selecionado como elemento centralizador das discussões emergentes. Com isso, o propósito passa 
de um contraste entre as opiniões de cada grupo à um contexto gerador de argumentos, os quais independem de sua origem, sendo este 0 enfoque eleito para análise neste artigo.

\section{ALGUNS ARGUMENTOS EMERGENTES}

As respostas obtidas pelos docentes constituintes dos grupos PMP, PFC e PUP estão ilustradas na Figura 3, e disponíveis em íntegra, respectivamente, nos links mostrados logo abaixo (garantindo-se 0 devido anonimato):

https://www.mentimeter.com/s/3639210aca30d4f19776c3d160e1bcf8/7148c899212d/edit, https://www.mentimeter.com/s/460d265524010709f322da0f7c554674/d49af2680edb/dit e https://www.mentimeter.com/s/e6be37a5fa0efac80a4795d15d9f6a96/366a8e43b7e4/edit.

Figura 3 - As respostas obtidas pelos docentes: uma ilustração.

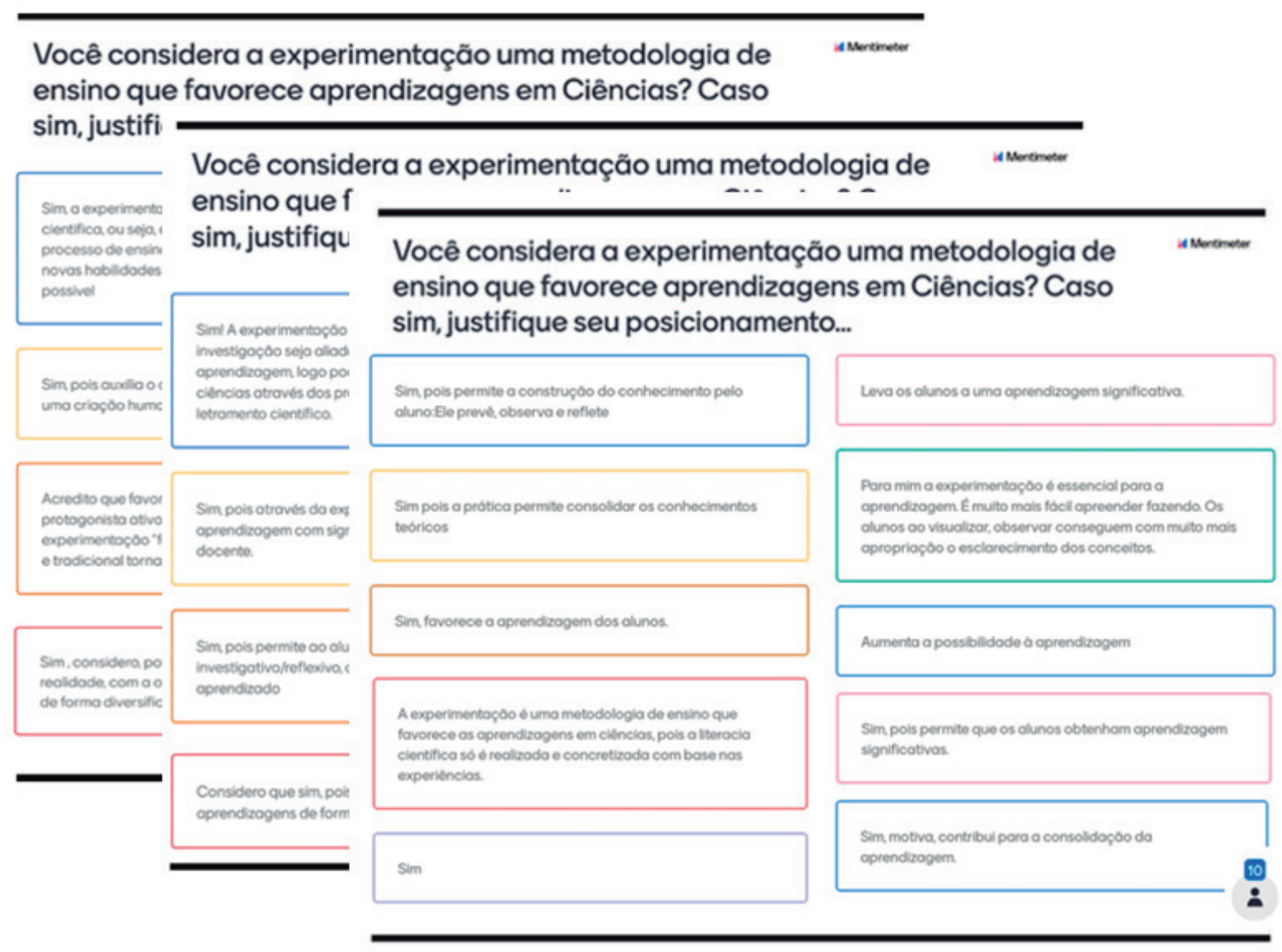

Fonte: construção do autor.

A análise das respostas combinadas permitiu uma síntese centrada em determinados argumentos, conforme se apresenta nos excertos mostrados no Quadro 2. 
Quadro 2 - Excertos/corpus da pesquisa.

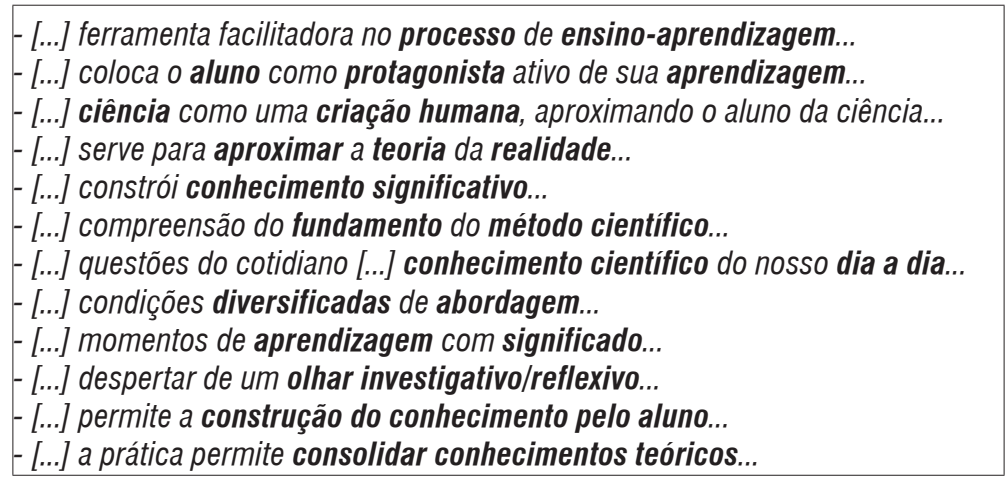

Fonte: construção dos autores.

Tendo em vista alguns elementos considerados como de relevância a uma análise que se aproxime dos fundamentos teórico-metodológico subjacentes à AEP, a partir dos elementos discursivos grifados no Quadro 2, foram identificadas duas linhas de argumentação, configurando-se em ATD como categorias do tipo emergentes, uma de dimensão pedagógica e outra epistemológica, conforme é sistematizado no Quadro 3.

Quadro 3 - Unidades de análise.

\begin{tabular}{|l|l|}
\hline \multicolumn{2}{|c|}{ LINHAS ARGUMENTATIVAS } \\
\hline \multicolumn{1}{|c|}{ PEDAGÓGICA } & \multicolumn{1}{c|}{ EPISTEMOLÓGICA } \\
\hline - processo; ensino-aprendizagem & - ciência; criação humana \\
- aluno; protagonista; aprendizagem & - aproximar; teoria; realidade \\
- conhecimento; significativo & - fundamento; método científico \\
- aprendizadas; abordagem significado & - conhecimento científico; dia a dia \\
- olhar investigativo/reflexivo & - construção do conhecimento pelo aluno \\
- consolidar conhecimentos teóricos & \\
\hline
\end{tabular}

Fonte: construção dos autores.

Para fins analíticos, tornou-se producente a proposição de um Metatexto direcionado a cada uma das categorias identificadas, a partir de argumentos que aproximam a experimentação às diretrizes da AEP e sustentam esta proposta como uma metodologia de ensino consolidada por fundamentos pedagógicos e epistemológicos, bem como por eles caracterizada, respectivamente nos pressupostos da Teoria da Aprendizagem Significativa e da Epistemologia de Thomas Kuhn, conforme explicita seu referencial. Sendo assim, se passará a tratar da sistematização de ambas composições teóricas, caracterizadas como a implicação da experimentação nos empreendimentos do ensinar e do aprender: aproximações aos fundamentos da AEP e Abordagens experimentais à Ciência pautadas por epistemologias contemporâneas. 


\section{A implicação da experimentação nos empreendimentos do ensinar e do aprender: aproximações aos fundamentos da AEP}

Estendendo um pouco mais as discussões quanto a fundamentação pedagógica da AEP, nota-se que se faz nela emprego de elementos teóricos próprios da Teoria da Aprendizagem Significativa. Isto, conforme proposições de Ausubel (2003), destacando-se as três condições imperativas à uma aprendizagem desta natureza (conhecimento prévio, material potencialmente significativo e pré-disposição do sujeito em aprender), aprendizagens significativas dos tipos por descoberta e por recepção e os conceitos/princípios da diferenciação progressiva e reconciliação integrativa, bem como a relação estabelecida entre eles e a programação dos conteúdos instrucionais. Cabe ainda menção de que tal teoria estabelece como aprendizagem de cunho significativo a conversão entre conhecimentos lógicos em psicológicos, interna à estrutura cognitiva do sujeito aprendiz (o aluno), sob potencial facilitação dos métodos e recursos aplicados/disponíveis pelo/ao instrutor (o professor).

Após socialização da estrutura organizacional da AEP junto aos públicos-alvo, seguida de iminente questionamento aberto com fins de investigação da percepção daqueles sujeitos quanto a eventuais favorecimentos aos processos do ensino e da aprendizagem oferecidos pela estratégia/técnica experimental, algumas unidades teóricas emergiram, tais como a processualidade do ensino e da aprendizagem e a concepção do aluno como um sujeito ativo de sua aprendizagem. Nesse enfoque, considera-se que 0 ensino experimental, quando capaz de repercutir em uma estratégia de ensino que se impõe sobre a técnica, quando gerador de questionamentos ao invés de oferecedor de respostas e concebido por professores e alunos como um processo didático-pedagógico de investigação e pesquisa, é capaz de reverberar em significados concretos e conhecimentos psicológicos. Para tanto,

[...] tomar a experimentação como parte de um processo pleno de investigação é uma necessidade, reconhecida entre aqueles que pensam e fazem 0 ensino de ciências, pois a formação do pensamento e das atitudes do sujeito deve se dar preferencialmente nos entremeios de atividades investigativas (GIORDAN, 1999, p. 44).

Tomando-se como premissa que uma aprendizagem de caráter significativo, gerador de um conhecimento psicológico e idiossincrático, requer o desenvolvimento de significados próprios pelo sujeito aprendiz, isto é, não mecânicos e literais, três afirmações inspiradas em Novak (1997) são oportunas: (a) os seres humanos são criadores de significados; (b) o objetivo da educação é a construção de significados compartilhados; (c) os significados compartilhados podem ser facilitados pela intervenção ativa de professores bem preparados. A atividade experimental, nos moldes da AEP, isto é, desencadeada por uma problemática aderente ao próprio meio dos sujeitos envolvidos no processo investigativo, é capaz de potencialmente conciliar os argumentos aos quais se fez referência logo acima, tendo em vista seu caráter dialógico e colaborativo.

Conforme elencado pelos respondentes da pesquisa desenvolvida, a experimentação consiste em uma abordagem diversificada de temáticas e conteúdos/objetos de conhecimento, promovendo, com isso, um olhar investigativo/reflexivo no aluno, o que certamente amplia suas potencialidades de aprendizagem. Nesse enfoque, aprendizagens significativas dos tipos descoberta e recepção são concomitantemente favorecidas pela abordagem experimental, tendo em vista os tratamentos metodológicos amplos e diversificados empregados na mediação do material instrucional. Rememorando e posicionando-se: 
[...] na aprendizagem por descoberta se impõe que o ser aprendente primeiramente descubra o que será aprendido, nas condições similares da Aprendizagem Significativa, como segue: conhecimento prévio adequado, material potencialmente significativo e predisposição para aprender. [...] A aprendizagem receptiva ou por recepção, por sua vez, ocorre quando 0 aprendiz "recebe" o conhecimento a ser aprendido no seu formato finalístico, o que não se caracteriza como aprendizagem passiva e nem se associa ao modo expositivo do ensino convencional (SILVA; MOURA, 2018, p. 50).

A atividade experimental, nas diretrizes aqui tratados e adjacentes à AEP, requer do aprendiz um exercício cognitivo interativo, a fim de sua caracterização do problema que a origina, em circunstâncias que 0 capacite a desenvolver/apresentar uma solução cientificamente aceitável e consistente à tal problema. Este exercício, contudo, demanda numerosos processos mentais associados, dentre eles a identificação de significados, ancoragem deles aos seus conhecimentos prévios e uma diferenciação progressiva e reconciliação integrativa, princípios integrantes e estruturadores da própria teoria (da Aprendizagem Significativa), no que diz respeito ao processo cognitivo da aprendizagem (AUSUBEL, NOVAK; HANESIAN, 1978; MOREIRA, 2012).

Além disso, ambos conceitos/princípios acima referidos repercutem em dois processos inter-relacionados que se desenvolvem no curso da aprendizagem, a partir de uma abordagem extrínseca ao sujeito aprendiz, diretamente vinculada à programação de métodos instrucionais, isto é, ao exercício docente. Conforme Ausubel (2003) propõe, é mais descomplicado aprender por diferenciação de conceitos do que pelo processo inverso (reconciliação). Assim, seria necessário partir de noções mais gerais para subsequentemente proceder à sua diferenciação, em vez de partir de conceitos mais específicos, intencionando sua reconciliação à medida que a instrução avança. Sendo assim, da diferenciação progressiva chega-se à reconciliação integrativa, o que faz com que a aprendizagem subordinada prevaleça à aprendizagem superordenada.

Em síntese, ambas ideias, aqui expressas conceitualmente, convergem em uma intervenção didática programada/orientada do geral ao específico, favorecida a partir da identificação e/ou caracterização de uma unidade contextual passível de integrar os conteúdos a serem trabalhados. Ganha relevância, nesse propósito, uma organização conteudinal interna, inteligível, desvinculada de uma sequência arbitrária de informações justapostas. No caso da AEP, em seu primeiro momento de intervenção - a discussão prévia, há condições favoráveis à sua estruturação a partir dos fundamentos sistêmicos da proposta, sua relacionalidade a dada situação concreta, ou a caracterização do problema proposto segundo princípios de sua identificação a uma unidade situacional conhecida em certo domínio. Em sua condução (do segundo momento em diante), remete-se à constantes retomadas ao problema originário, tendo em vista as unidades de compreensão emergentes do fazer procedimental e de suas discussões circunscritas. Nesse estado, toda aprendizagem que resultar em reconciliação integrativa potencialmente resultará também em diferenciação progressiva, doravante os métodos empregados.

À guisa disso, outro elemento de discussão é imperativo de análise, pois estudos mostram que

[...] muitos professores ainda possuem uma visão simplista a respeito da experimentação, a qual perpassa por uma função comprobatória de determinadas teorias, sob uma perspectiva de dicotomia entre conhecimentos teóricos e práticos, e então acabam por não enfatizar seu caráter naturalmente investigativo (SILVA; MOURA, 2018, p. 22). 
Sendo assim, diretamente associada às perspectivas pedagógicas do ensino, isto é, à intencionalidade de emprego do método experimental para concretude de uma proposta pedagógica, tal como 0 desenvolvimento da Alfabetização Científica, nos pressupostos de Fourez (1995), ou tendo-se a divulgação das Ciências como norte, com base em Candotti (2001), dentre outros exemplos passíveis de referência, requer-se uma atenção particular aos julgamentos científico-epistemológicos dos sujeitos envolvidos. 0 modelo de Ciência que se concebe e o tipo de conhecimento e de atitude científico(a) que se deseja desenvolver são questões-chave à reflexão fundamentada, preferencialmente prévias às abordagens didáticas de sala de aula ou outro ambiente formal de ensino. Em amparo a este juízo, estudos mostram que as concepções científicas do professor de Ciências são levadas à sua sala de aula (bem como aos seus ambientes de prática), mesmo que implícitas, e repercutem em grande medida nos modos pelos quais seus alunos irão percebê-la ao longo de sua vida (CACHAPUZ et al., 2011). Isso reafirma a imprescindibilidade desta discussão.

\section{Abordagens experimentais à Ciência pautadas por epistemologias contemporâneas}

A partir do questionamento realizado, no que tange às percepções do público-alvo quanto ao efetivo favorecimento da metodologia experimental aos processos do ensino e da aprendizagem, foram identificados elementos de natureza aderente aos estudos integrados à Epistemologia da Ciência, destacando-se a Ciência como uma criação humana, aproximações entre teorias científicas e realidade e relações entre o método científico e contextos cotidianos. Percebe-se, com isso, uma preocupação destes professores quanto às repercussões da caracterização/concepção científica antecedente à sua práxis docente, uma vez que os procedimentos didáticos se materializam a partir de uma intenção pedagógica, e esta, por sua vez, é diretamente influenciada pelas percepções ontológicas e epistemológicas de Ciência de seus professores.

A adoção de posicionamento onde o conhecimento científico apresenta natureza neutra, desvinculada da realidade e dos interesses sociais, marca atualmente ainda tão presente em sala de aula, além de altamente preocupante em teores de sua aprendizagem, é incompatível aos pressupostos epistemológicos hodiernos implicados à Ciência. E, como ponto de partida dessa reflexão, considera-se que o corriqueiro comportamento discente de desatenção, desagrado e, em alguns casos aversão aos conteúdos de natureza científica, é fomentado por desajustes entre a Ciência que lhes é apresentada em ambientes formais e suas próprias vidas. Esta percepção é certamente favorecida pela atuação docente quando este professor expõe o conhecimento científico de modo restrito às informações pontuais, fragmentadas e desvinculadas de zonas de interesse individual e de repercussões sociais. Tendo em vista, até este tempo, que os discentes encontram dificuldades conceituais e de uso de estratégias e métodos próprios do trabalho científico em sala de aula, Ihes é reforçada uma percepção da existência de conteúdos científicos de natureza própria, restrita ao contexto dos "cientistas" e "fazedores" desses saberes. E, nas particularidades da concepção docente, nota-se que não é incomum esses sujeitos confundirem dados procedimentos necessários à aprendizagem da Ciência à métodos próprios de produção do conhecimento científico, onde, em muitos casos, as técnicas impõem-se às estratégias didático-pedagógicas (WELLINGTON, 1989).

Nessa linha de reflexão, Pozo e Crepo (2009, p. 18) apontam importantes características da conduta dos discentes frente aos conteúdos científicos que lhes são apresentados nos ambientes formais de ensino, argumentando que 
[...] os alunos tendem a assumir atitudes inadequadas com respeito ao trabalho científico, assumindo posições passivas, esperando respostas em vez de dá-las, e muito menos são capazes de fazer eles mesmos as perguntas; também tendem a conceber os experimentos como "demonstrações" e não como pesquisas; a assumir que 0 trabalho intelectual é uma atividade individual e não de cooperação e busca conjunta.

Todavia, a imagem de Ciência com foco em refletir a realidade, ou mesmo com compromissos vinculados a este propósito, pautando-se pela aplicação em rigor de determinado método científico, apesar de superada pelas epistemologias contemporâneas, ainda é vigente em meios de comunicação/divulgação e está fortemente enraizada na escola. Impõe-se aos docentes movimentos didático-pedagógicos capazes de ir de encontro a essa vertente (neo)positivista, discutindo acerca de um conhecimento científico não extraído da realidade, mas pautado pela construção de modelos/teorias no propósito de conferência de sentido a esta realidade (CACHAPUZ et al., 2011; POZO; CRESPO, 2009). Nessa conjuntura, ganha relevância a noção de que a

[...] a ciência não é um discurso sobre o "real", mas um processo socialmente definido de elaboração de modelos para interpretar a realidade. As teorias científicas não são saberes absolutos ou positivos, mas aproximações relativas, construções sociais que, longe de "descobrii" a estrutura do mundo ou da natureza, constroem ou modelam essa estrutura (POZO; CREPO, 2009, p. 20).

No que tange, uma vez mais, ao ensino das Ciências como foco das discussões, nas particularidades do/pelo método da experimentação via AEP, o tratamento de conteúdos como saberes históricos e provisionais, capazes de envolver os alunos em suas representações, na condução de possíveis soluções ao problema que origina a AEP, o fomento de dúvidas e de incertezas frente aos dados coletados/ gerados e pertinência deles quanto ao problema estabelecido, surgem como requisitos essenciais a um processo de aprendizagem psicológico e significativo. A inteligibilidade do problema proposto, neste enfoque, é uma condição imperativa à geração de interpretações salutares emergentes dos resultados experimentais obtidos, à fim do desenvolvimento de uma solução aceitável a ele, capaz de gerar convencimento aos alunos e propriedades argumentativas consistentes no momento de sua socialização. Tais habilidades interpretativas subjazem ao sistema cognitivo humano, o qual apresenta características específicas condicionantes à aprendizagem de um objeto de instrução, consideravelmente mais próximas da interpretação do que da literalidade das informações (POZO, 1996).

Nesse quadro teórico, a função didática do professor, ao propor e, de certo modo, conduzir um processo experimental, altera-se expressivamente, pois lhe cabe transferir o controle de boa parte das ações aos seus alunos, os oportunizando a tomar decisões próprias e efetivamente envolverem-se nos métodos empregados no laboratório (ou em outro ambiente de prática), quesitos favorecedores a uma aprendizagem com nuances significativos. Nessa linha argumentativa, a epistemologia proposta por Thomas Kuhn abriga alegações que apresentam um conhecimento científico inato às percepções e intenções próprias dos sujeitos que o praticam, visão altamente salutar à didática da Ciência sob propósitos do trabalho docente, a partir de seus pressupostos epistemologicamente contemporâneos (KUHN, 1998). 
Sacristán e Gómez (1998, p. 100) trazem alguns elementos essenciais à consideração, tendo em vista 0 ensino de conteúdos científicos emergentes de uma percepção docente exposta logo acima, capazes de oportunizar condições favoráveis à sua aprendizagem significativa, tais como "[...] 0 objeto de investigação, o tipo de problemas que colocar e resolver, a própria essência dos processos de investigação, as estratégias, as técnicas e os instrumentos que se consideram mais adequados e os critérios de validação e legitimação do conhecimento". Como estratégia metodológica, Kuhn (1962) incentiva a elaboração do que denomina de guia de planejamento experimental ao tratar do planejamento adaptativo entre 0 conhecimento de natureza teórica e experimental, 0 que em AEP leva a denominação de diretrizes metodológicas. Ambas premissas se prestam ao mesmo fim: garantir condições metodológico-organizacionais necessárias ao desenvolvimento de uma experimentação capaz de suscitar aprendizagens significativas em Ciências.

Em síntese, os pressupostos kuhnianos que subjazem a AEP concebem um conhecimento científico altamente marcado pela percepção e subjetividade humanas, com respeito às demarcações e argumentações utilizadas/empregadas. Além disso, é destacada a configuração de um modelo experimental capaz de um tratamento científico adaptativo ao teórico, isto é, nem refutativo, nem comprobatório, mas tomado com propósito de apresentar dados e conteúdos a partir de outras estratagemas, além da corrente linguagem teórico-matemática, e com isso oportunizar novas perturbações cognitivas aos aprendentes. Tais movimentos didáticos aproximam-se dos fundamentos psicológicos da Teoria da Aprendizagem Significativa, tendo em vista a imprescindibilidade da mobilização à aprendizagem e as múltiplas facetas nela imbricadas. É sabido que não se aprende pelo outro, o professor, mas que este ator exerce importantes funções de favorecimento de aprendizagens ao desenvolver e aplicar estratégias capazes de manipular objetos de conhecimento de modo lógico, coerente e inteligível junto aos seus discentes (KUHN, 2000; AUSUBEL, 1978; 2003).

\section{CONSIDERAÇÕES FINAIS}

A partir de intervenções realizadas junto a professores de distintos contextos apresentando os fundamentos pedagógicos e epistemológicos da AEP, os quais a configuram como uma proposta teórico-metodológica ao ensino experimental das Ciências, argumentações emergiram, permissivas de aprofundamentos e potencial geração de novas acepções. Em uma perspectiva de síntese, tratou-se de implicações da experimentação aos empreendimentos do ensinar e do aprender, bem como sobre a relevância em se fomentar um Ensino de Ciências a partir de abordagens experimentais permissivas à construção de uma imagem científica epistemologicamente contemporânea, isto é, aberta às interpretações e próxima à subjetividade delas inerente. Adentrando-se às discussões particulares à AEP, foram demarcadas suas potenciais contribuições ao processo do ensino, destacando-se a premência de uma mediação didática atenta à aprendizagem, bem como da própria aprendizagem, com foco nos fatores psicológicos adjacentes ao processo cognitivo de apropriação de objetos de conhecimento científicos.

Ao se utilizar da experimentação tendo-se como meta um ensino gerador de aprendizagens significativas, ou intencionado para tal, percebe-se nos entremeios dos procedimentos práticos da AEP variadas condições satisfatórias para abordagens e tratamentos aos conteúdos científicos de suporte, além da natureza própria da experimentação como linguagem científica. Costuma-se, nos ambientes pedagógicos, favorecer outras abordagens para temas científicos, como a descritiva, a matemática, a gráfica, por exemplo, em detrimento à experimental, o que por si descaracteriza a 
Ciência de suas bases configuradoras, além de distanciá-la da realidade dos alunos. Mesmo ao se assumir posição de aceite da existência de importantes distinções entre a produção do conhecimento científico e sua aprendizagem, deve-se reconhecer que nos ambientes escolares se desenvolvem os primeiros contatos dos alunos a uma forma própria de caracterização deste tipo de conhecimento. Sendo assim, abordagens epistemológicas favoráveis a uma percepção não determinista da Ciência, mas dependente de entendimentos e aberta à interpretações distintas são fundamentais ao desejável, isto é, à aprendizagem significativa de seus conceitos, princípios e teorias.

Ao apresentar o conhecimento científico como articulado ao contexto cotidiano, do qual este é dependente e exerce grande influência de apropriação e transformação, abrem-se possibilidades de conversões lógicas em psicológicas, a partir de uma ampliação de significados. Em acréscimo, o tratamento de conteúdos científicos sob uma perspectiva de construção social, e não como uma apropriação do real, favorece a esta apropriação, tendo em vista que aproxima os sujeitos a um tipo particular de conhecimento, o qual busca o entendimento de seus fundamentos para chegar-se em melhores leituras às causas e aos efeitos observados.

A AEP, por sua vez, pretende, por meio de um planejamento e mediação, abranger dadas condições permissivas à caracterização de um tratamento científico adjacente à esta concepção de Ciência, no âmbito da qual os sujeitos assumem uma posição de destaque, protagonismo e autonomia. Ao conter articuladores e momentos próprios, isto é, uma sistematização organizacional comprometida a um ensino capaz de oportunizar aprendizagens, sob fundamentos da Teoria da Aprendizagem Significativa, e fomentar uma concepção científica sob diretrizes desencadeadas da Epistemologia de Thomas Kuhn, esta estratégia didático-pedagógica é apresentada como oportuna para apropriações, aplicações, avaliações e aproximações a variados contextos e realidades educacionais, com expectativa voltada ao Ensino de Ciências. Tal percepção foi ratificada pelos resultados deste artigo, sob um viés de alternância e interdependência entre elementos pedagógicos e epistemológicos; percepção esta que reforça a premência de apresentação/manipulação didática de um conhecimento em Ciências aderente ao meio social dos sujeitos nele imbricados, o que favorece leituras próprias e, com isso, aprendizagens.

\section{REFERÊNCIAS}

AUSUBEL, D. P. Aquisição e Retenção de Conhecimentos: uma perspectiva cognitiva, Lisboa: Editora Plátano, 2003.

AUSUBEL, D. P. Educational Psychology: a cognitive view, 1. ed. New York: Holt Mc Dougal, 1978.

AUSUBEL, D. P. ; NOVAK, J. D., HANESIAN, H. Psicologia Educacional. Rio de Janeiro: Editora Interamericana, 2. ed., 1980.

CACHAPUZ, A., GIL-PEREZ, D., PESSOA DE CARVALHO, A. M., PRAIA, J.; VILCHES, A. A necessária renovação do Ensino das Ciências. São Paulo: Cortez Editora, 2011.

CANDOTTI, E. Divulgação e democratização da ciência. Ciência \& Ambiente, Santa Maria, n. 23, p. 5-13, jul./dez, 2001. Disponível em: http://w3.ufsm.br/reciam/. Acesso em: 12 out. 2019.

CHALMERS, A. F. 0 que é essa coisa chamada Ciência, afinal? São Paulo: Ed. Brasiliense, 1999. 
DAMIANI, M. G., ROCHEFORT, R. S., CASTRO, R. F., DARIZ, M. R.; PINHEIRO, S. S. Discutindo pesquisas do tipo intervenção pedagógica. Cadernos de Educação. UFPel - Pelotas [45] 57 - 67, maio/agosto, 2013. Disponível em: https:// bit.ly/3G3nq0E. Acesso em: 17 nov. 2018.

FOUREZ, G. A construção das ciências: introdução à filosofia e à ética das ciências. São Paulo: Ed. UNESP, 1995.

GALIAZZI, M. C.; GONÇALVES, F. P. A natureza pedagógica da experimentação: uma pesquisa na licenciatura em química. Química Nova, v. 27, n. 2, p. 326-331, 2004. Disponível em: https://bit.ly/3G4qART. Acesso em: 2 dez. 2020.

GIORDAN, M. 0 papel da experimentação no Ensino de Ciências. Química Nova na Escola, n. 10, p. 43-49, 1999. Disponível em: https://bit.ly/3phbP8p. Acesso em: 7 nov. 2020

HODSON, D. Hacia un enfoque más crítico del trabajo de la laboratório. Enseñanza de las Ciencias, v. 12, n. 3, p. 299-313, 1994. Disponível em: https://ensciencias.uab.es/issue/archive. Acesso em: 21 out. 2020

KUHN, T. S. The road since structure. Chicago: The University of Chicago Press, 2000.

KUHN, T. S. A estrutura das revoluções científicas. 5. ed. São Paulo: Perspectiva, 1998.

LATOUR, B.; WOOLGAR. A vida de laboratório. Rio de Janeiro: Relume Dumará, 1997.

MORAES, R.; GALIAZZI, M. C. Análise Textual Discursiva. Editora Unijuí. ljuí, 2006.

MORAES, R. Uma tempestade de luz: a compreensão possibilitada pela análise textual discursiva. Ciência \& Educação, v. 9, n. 2, p. 191-211, 2003.

MOREIRA, M. A. 0 que é afinal Aprendizagem Significativa? Qurriculum, La Laguna, Espanha, 2012.

MOREIRA, M. A. A teoria da aprendizagem significativa e sua implementação em sala de aula. Brasília/DF, UnB, 2006.

MOREIRA, M. A. Uma abordagem cognitivista ao Ensino de Física: a teoria de Aprendizagem de David Ausubel como sistema de referência para a organização do Ensino de Ciências. Porto Alegre, Editora da Universidade, UFRGS, 1983.

MOREIRA, J. R., SILVA, A. L. S., MOURA, P. R. G.; DEL PINO, J. C. Potencialidade de um plano de ensino pautado na Atividade Experimental Problematizada (AEP) à Alfabetização Científica em Química. Experiências em Ensino de Ciências, v. 14, n. 2, p. 558-581, 2019. Disponível em: https://bit.ly/3IXR8vU. Acesso em: 12 set. 2020

NOVAK, J. D. Retorno a Clarificar con Mapas Conceptuales. Em: Encuentro Internacional sobre el aprendizaje significativo. Burgos: Servivio de Publicaciones de la Universidad de Burgos, 1997.

POZO, J. I. Aprendices y maestros. Madrid: Alianza/Psicologia Minor, 1996.

POZO, J. I.; CRESPO, M. A. G. A aprendizagem e o ensino de ciências: do conhecimento cotidiano ao conhecimento científico. Porto Alegre: Artmed, 2009. 
PRAIA, J. F., CACHAPUZ, A. F. C.; GIL-PÉREZ, D. Problema, teoria e observação em Ciência: para uma reorientação epistemológica da Educação em Ciência. Ciência \& Educação, v. 8, n. 1, p. 127-145, 2002. Disponível em: https://bit.ly/ 3IYTmex. Acesso em: 30 fev. 2020.

PRIGOGINE, I. 0 fim das certezas: tempo, caos e as leis da natureza. São Paulo. Editora UNESP, 2002.

SACRISTÁN, J. G.; GÓMES, A. I. P. Compreender e transformar o ensino. 4. ed. Artmed, 1998.

SANTOS, W. L. P. Educação científica humanística em uma perspectiva freireana: Resgatando a Função do Ensino de CTS. Alexandria Revista de Educação em Ciência e Tecnologia, v. 1, n 1, p. 109-131, 2008. Disponível em: https://bit.ly/ 3pgJWNH. Acesso em: 12 out. 2019.

SILVA, A. L. S., MOURA, P. R. G.; DEL PINO, J. C. Atividade Experimental Problematizada: uma proposta de diversificação das atividades para o Ensino de Ciências. Experiências em Ensino de Ciências, v. 10, n. 3, p. 51-65, 2015. Disponível em: https://bit.ly/3E27qdk. Acesso em: 12 out. 2019.

SILVA, A. L. S., MOURA, P. R. G.; DEL PINO, J. C. Atividade Experimental Problematizada (AEP) como uma estratégia pedagógica para o Ensino de Ciências: aportes teóricos, metodológicos e exemplificação. Experiências em Ensino de Ciências, v. 12, n. 5, p. 177-195, 2017. Disponível em: https://bit.ly/3AZ1Bvw. Acesso em: 2 jun. 2020.

SILVA, A. L. S., MOURA, P. R. G.; DEL PINO, J. C. Subsídios pedagógicos e epistemológicos da Atividade Experimental Problematizada. REVELLI. v. 10 n. 4, p. 41-66, 2018. Disponível em: https://bit.ly/3BZcper. Acesso em: 12 out. 2019.

SILVA, A. L. S., FERREIRA, M., PEREIRA, S. M.; FILHO, O. L. S. Atividade Experimental Problematizada (AEP): revisão bibliográfica em descritores na área de Ensino de Ciências. Revista Pesquisa e Debate em Educação, v. 9, n. 1, p. 459-471, 2019.

SILVA, A. L. S.; NOGARA, P. A. Atividade Experimental Problematizada (AEP) - 60 experimentações com foco no ensino de Química: da educação básica à universidade. Appris. Curitiba/PR, 2018.

SILVA, A. L. S.; MOURA, P. R. G. Ensino Experimental de Ciências - uma proposta: Atividade Experimental Problematizada (AEP). Livraria da Física. São Paulo/SP, 2018.

WELLINGTON, J. Skills and processes in Science Education. Londres: Routledge, 1989.

ZUCCO, C. Graduação em Química: avaliação, perspectivas e desafios. Química Nova, v. 30, n. 6, p. 1429-1434, 2007.

RECEBIDO EM: 19 abr. 2021

CONCLUÍDO EM: 04 out. 2021 